\title{
Impact of temperature variability and management interventions on productivity of wheat
}

\author{
B.B. VASHISHT and S.K. JALOTA \\ Department of Soil Science, Punjab Agricultural University, Ludhiana 141004, Punjab \\ Corresponding author E-mail: bharatpau@pau.edu
}

\begin{abstract}
Field experiments for six seasons (2008-09 to 2013-2014) and simulations for mid-century (2021-2050) were carried out to (i) understand impact of inter- and intra- seasonal temperature variability on wheat yield, and (ii) identify best management intervention in relation to temperature variability. In the field experiments, treatments were three dates of planting, two inbred varieties and two irrigation schedules replicated thrice. Simulation with CERES-Wheat model pointed that variability of 5.5 percent in Tmax and 3.8 percent in Tmin would cause 11.2 percent variability in yield. The variation in yield would also vary with date of planting. It was relatively less in Nov 05 sown wheat than other dates,showing that in mid-century yield can be sustained by planting wheat at this date. However, at present growing of longer duration varieties in last week of October with adequate irrigation, medium to longer duration in $1^{\text {st }}$ week of November is the practical adaptive measure to minimize impact of temperature variability on wheat yield.
\end{abstract}

Key words : Temperature variability, weather descriptors, wheat yield, CERES-Wheat model

Wheat is the major winter crop grown on area of 3.5 million hectares out of a total cultivated area of 4.2 million hectares in the Punjab state. There are large gaps between potential yields, experimental yields and farmers'yields in this region (Ladha et al., 2003). For potential productivity, the irrigated wheat requires cool climate during early growth and no heat stress at reproductive and grain development phases (Farooq et al., 2011). Changes in global climate are likely to influence spatial and temporal trends of temperature and rainfall, which will affect crop phenology and yield (Jalota and Vashisht, 2016). A gradual or abrupt change in weather parameters especiallymaximum temperature(Tmax) and minimum temperature (Tmin) compared to apposite can adversely impact growth and yield of wheat. As climate conditions are inherently variable from year to year, it may cause inter- and intra-seasonal variation in temperature and subsequently the wheat yield. It is expected that the yearly variation in wheat yield could be more in future due to exacerbated climate variability.For ensuring regional food security in future, it is important to evaluate climate variability and change effects on wheat yield and devises practices to mitigate the same. Agricultural system models are commonly used to investigate the potential impact of climate variability on crop productivity.Decision Support System for Agrotechnology Transfer (DSSAT) has been extensively used for yield gap analysis, strategic and tactical decision making and climate change studies (Vashisht et al.,
2013).Reports in the literature suggest that wheat yield is governed not only by the change in temperature during the entire growth season, but at a particular stage too (Farooq et al., 2011).To moderate temperature change/variability effects, management interventions such as planting date, crop variety and irrigation schedules have been advocated in the literature (Jalota et al., 2013). Considering this, the present field and simulation studies were undertaken at Ludhiana location of central Punjab to (i) understand impact of inter-and intra-seasonal temperature variability on wheat yield in present and future climates, (ii) identify best management intervention such as planting date, variety and irrigation schedule in relation climate variation.

\section{MATERIALS AND METHODS}

\section{Field studies}

Field experiments on wheat following rice were conducted at the research farm of Punjab Agricultural University, Ludhiana ( $30^{\circ} 56^{\prime} \mathrm{N}, 75^{\circ} 52^{\prime} \mathrm{E}$ and $247 \mathrm{~m}$ amsl). The treatments included three dates of planting viz. October 20 (D1), November 05 (D2) and November 20 (D3); two inbred varieties viz. long duration of 160 days (V1-PBW 343/621) and medium duration of 146 days (V2-PBW 550), and two irrigation schedules viz. five irrigations based on crop stage-crown root initiation, tillering, jointing, flowering and grain formation (I1), and three to four irrigations based on IW/PAN-E ratio of 0.9 (I2). In the long duration varieties, 
Table 1: Effect of year, planting date, irrigation and variety on wheat yield $\left(\mathrm{kg} \mathrm{ha}^{-1}\right)$

\begin{tabular}{|c|c|c|c|c|c|c|c|c|}
\hline \multirow[t]{2}{*}{ Year } & \multirow[t]{2}{*}{ Mean } & \multicolumn{3}{|c|}{ Date of planting } & \multicolumn{2}{|c|}{ Irrigation } & \multicolumn{2}{|c|}{ Cultivar } \\
\hline & & Oct-20 & Nov-05 & $\overline{N o v-20}$ & I1 & $\mathrm{I} 2$ & V1 & $\mathrm{V} 2$ \\
\hline 2008-09 & 4176 & 3970 & 4617 & 3940 & 4392 & 3960 & 4370 & 3982 \\
\hline $2009-10$ & 4376 & 4597 & 4317 & 4215 & 4542 & 4211 & 4435 & 4318 \\
\hline 2010-11 & 5020 & 4956 & 4830 & 5274 & 5033 & 5007 & 5189 & 4851 \\
\hline $2011-12$ & 4249 & 4283 & 4359 & 4105 & 4330 & 4167 & 4417 & 4081 \\
\hline $2012-13$ & 4064 & 4388 & 3796 & 4009 & 4112 & 4016 & 4082 & 4046 \\
\hline 2013-14 & 4914 & 5420 & 4719 & 4603 & 4998 & 4830 & 5021 & 4807 \\
\hline Mean & 4467 & 4602 & 4440 & 4358 & 4568 & 4365 & 4586 & 4348 \\
\hline $\mathrm{CD}(0.05)$ & 304 & NS & 94 & 83 & & & & \\
\hline
\end{tabular}

I1 -irrigation at growth stages, I2- irrigation based on IW/ PAN ratio of 0.9 (I2); V1- variety PB 343/PBW 621, V2-variety PBW 550

PBW 343 was planted for first three years and PBW 621 for remaining years.In 2 irrigation was scheduled when ratio of depth of irrigation water (IW) to cumulative pan evaporation minus rainfall reached a 0.9 . Ratio was started after first irrigation (on the day $30^{\text {th }}$ after planting). A total of 12 treatments were replicated three times in plots of $40 \mathrm{~m}^{2}$ $(10 \mathrm{~m} \times 4 \mathrm{~m})$ in a split plot design. At planting $60 \mathrm{~kg} \mathrm{~N}, 30 \mathrm{~kg}$ $\mathrm{P}_{2} \mathrm{O}_{5}$ and $30 \mathrm{~kg} \mathrm{~K}_{2} \mathrm{O}^{-1}$ were applied. Second dose of $\mathrm{N}$ (60 $\mathrm{kg} \mathrm{ha}^{-1}$ ) was applied after first irrigation. The impact of interyear variation in temperature on crop yield was evaluated by developing relationships of averaged seasonal temperature and crop yield.

\section{Apposite temperature and temperature sensitivity}

Apposite Tmax and Tmin were estimated by fitting polynomial function to a simulated yield and observed temperature data for 20 years (1989-2008), in which the inter-seasonal Tmax and Tmin varied from $22.4-29.7^{\circ} \mathrm{C}$; and $9.1-15.9^{\circ} \mathrm{C}$, respectively. Sensitivity of crop yield to temperature in different growth periods was evaluated by developing a multiplicative model (Equation 1) from the field data.

$$
\mathrm{Y} / \mathrm{Ymax}= \pm \prod_{\mathrm{I}=1}^{\mathrm{n}}(\mathrm{Temp} / \text { Apposite Temp })^{\gamma}
$$

Where $\mathrm{Y}$ is actual yield $\left(\mathrm{kg} \mathrm{ha}^{-1}\right), \mathrm{Y}_{\text {max }}$ is highest observed yield $\left(\mathrm{kg} \mathrm{ha}^{-1}\right)$, Temp is temperature $\left({ }^{\circ} \mathrm{C}\right), \pm$ is intercept, $\Pi$ is multiplicative, $\gamma$ is sensitivity coefficient and $\mathrm{i}$ to $\mathrm{n}$ is number of stages during plant growth.

\section{Simulation studies}

Crop yield of wheat (variety - PBW 343/621 and PBW 550) was predicted using the already calibrated and validated CERES-wheat crop growth model (Vashisht et al., 2013). The weather data on Tmax, Tmin and rainfall (RF) used was the observed at meteorological station at Punjab Agricultural University for the present time slice (19892008) and projected under A1B scenario were derived from regional climate model PRECIS for mid-century, MC, (20212050). The corrected modeled data for mid-century (Jalota et al., 2013, Kaur et al., 2015) were grouped in six time slices as MC1 (2021-2025), MC2 (2026-2030), MC3 (20313035), MC4 (2036-2040), MC5 (2041-2045) and MC6 (2046-2050). Carbon dioxide $\left(\mathrm{CO}_{2}\right)$ levels taken were 388, 418, 447, 483 and 522 ppm in years 2010, 2020, 2030, 2040 and 2050, respectively, as per Bern model (IPCC: www.ipccdata.org/ancillary/tar-bern.txi).

\section{RESULTS AND DISCUSSION}

\section{Field studies}

Wheat yield : Averaged across treatments, the mean wheat yield of six years was $4467 \pm 402 \mathrm{~kg} \mathrm{ha}^{-1}$ However, it varied in different years, e.g., in the year 2010-11 was comparable to 2013-14 and was significantly higher (644-956 kg $\mathrm{ha}^{-1}$ ) compared to other years (Table 1). The mean yields for planting dates of Oct 20, Nov 05 and Nov 20 were $4602 \pm$ $518,4440 \pm 374$ and $4358 \pm 506 \mathrm{~kg} \mathrm{ha}^{-1}$, respectively, which differed non-significantly. Under I1 the mean yield was $4568 \pm 373 \mathrm{~kg} \mathrm{ha}^{-1}$, which was significantly higher than under I2 (4365 $\left.\pm 442 \mathrm{~kg} \mathrm{ha}^{-1}\right)$. Under V1 yield of $4586 \pm 425$ $\mathrm{kg} \mathrm{ha} \mathrm{H}^{-1}$ was significantly higher than V2 $(4348 \pm 390 \mathrm{~kg}$ ha' ${ }^{-1}$.

Field experiments also revealed that during six years of experimentation, wheat yield increased with inter-seasonal Tmax and Tmin, which ranged from $21.5-24.4^{\circ} \mathrm{C}$ and 8.5 $10.2^{\circ} \mathrm{C}$, respectively. This may be ascribed to the fact that average seasonal Tmax and Tmin in the present study period 

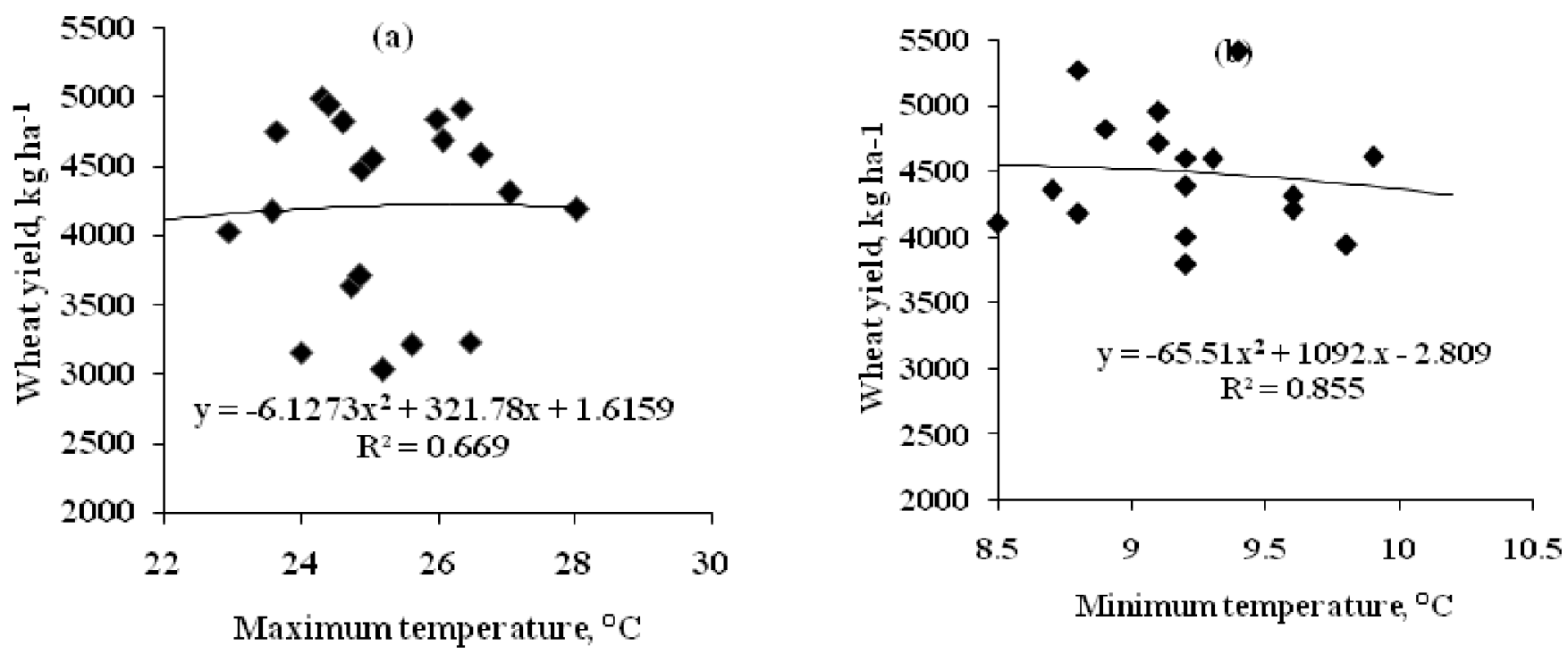

Fig 1: Effect of twenty years (1989-2008) averaged seasonal maximum and minimum temperatures on simulated wheat yield
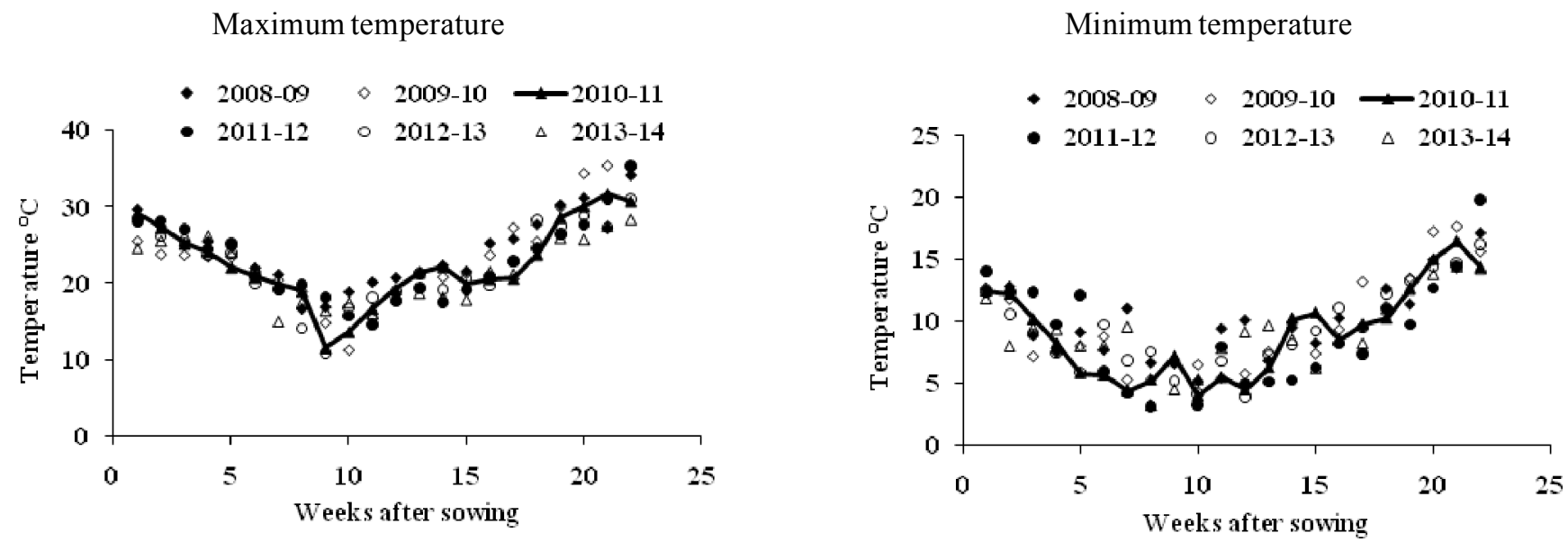

Fig2: Weekly air temperature in wheat crop season

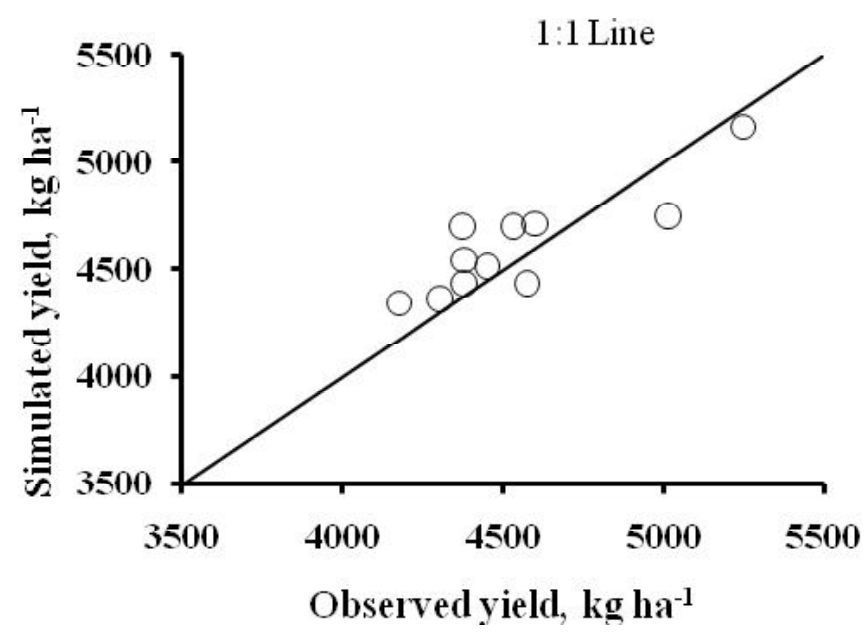

were within the optimum or apposite temperature limits of $20-25^{\circ} \mathrm{C}$ Tmax and $5-10^{\circ} \mathrm{C}$ Tmin, reported by Porter and Gawith(1999). However, in simulation study(1989-2008) it was observed that the inter-seasonal Tmax and Tmin varied from $22.4-29.7^{\circ} \mathrm{C}$; and $9.1-15.9^{\circ} \mathrm{C}$, respectively and wheat yield followed a polynomial function with temperature. The wheat yield started declining beyond $27^{\circ} \mathrm{C}$ and $11^{\circ} \mathrm{C}$ of Tmax and Tmin, respectively (Fig. 1).Increased temperatures impart negative impact of on crop production by reducing the length of the growing period of wheat (Jalota et al., 2013; Jalota and Vashisht, 2016;Zacharias et al., 2014; Kingra, 2016).

The wheat yield may also be influenced by the intraseasonal variation. The yield was higher in 2010-11 than other years, thus, intra-seasonal weekly Tmax and Tmin was taken as apposite temperatures and is represented by solid

Fig 3: Observed and simulated yield of wheat in different years and dates of sowing 
Table 2: Percent inter- seasonal variability in Tmax, Tmin and wheat yield in different time slices of mid century

\begin{tabular}{lcccc}
\hline Time slice & Oct-20 & Nov-05 & Nov-20 & Average \\
\hline 2021-2025 & 3.5 & 4.0 & 3.6 & 3.7 \\
2026-2030 & 6.2 & 6.2 & 6.0 & 6.1 \\
2031-2035 & 5.0 & 4.4 & 5.7 & 5.0 \\
2036-2040 & 5.2 & 4.6 & 3.5 & 4.4 \\
2041-2045 & 5.5 & 4.7 & 4.1 & 4.8 \\
2046-2050 & 9.0 & 8.7 & 8.6 & 8.8 \\
Average & 5.7 & 5.4 & 5.2 & 5.5 \\
& & Tmin & & \\
2021-2025 & 3.8 & 2.6 & 2.8 & 3.1 \\
2026-2030 & 4.0 & 4.0 & 4.0 & 4.0 \\
2031-2035 & 2.6 & 2.0 & 1.4 & 2.0 \\
2036-2040 & 6.7 & 6.2 & 4.7 & 5.9 \\
2041-2045 & 2.4 & 4.1 & 4.4 & 3.6 \\
2046-2050 & 4.6 & 4.2 & 3.3 & 4.0 \\
Average & 4.0 & 3.8 & 3.4 & 3.8 \\
& & Yield & & \\
2021-2025 & 12.3 & 11.4 & 17.1 & 13.6 \\
2026-2030 & 8.3 & 11.7 & 20.0 & 13.3 \\
2031-2035 & 9.8 & 8.1 & 7.9 & 8.6 \\
2036-2040 & 11.4 & 6.8 & 15.0 & 11.1 \\
2041-2045 & 14.4 & 5.1 & 14.2 & 11.3 \\
2046-2050 & 13.5 & 7.1 & 7.2 & 9.3 \\
Average & 11.6 & 8.4 & 13.6 & 11.2 \\
\hline
\end{tabular}

lines in Fig.2. On comparing periodic Tmax and Tmin of apposite temperatures (2010-11) with other years, it was observed that most of the time Tmax and Tmin (especially) remained higher than apposite temperature and caused yield decline.

\section{Simulation studies}

Prior to use DSAAT-CSMv4.5 for simulation of wheat yield, the indicators of model performance viz root mean square error (RMSE), modeling efficiency $(M E)$ and index of agreement $(d)$ were estimated, which were $0.05,0.40$ and 0.77 during calibration, and $0.04,0.40$ and 0.84 during validation, respectively. The model predicted yield matched closely to the observed (Fig. 3) owing to its sensitivity to the changes in temperature (Subash and Ram Mohan, 2012; Vashisht et al., 2013).
Table 3:Intra- seasonal variability (percent) in Tmax and Tmin in different growth period of wheat and time slices of mid century

\begin{tabular}{llll}
\hline Growth period & Time slice & Tmax & Tmin \\
\hline Germinate - Term Spklt & $2021-30$ & 5.0 & 8.0 \\
& $2031-40$ & 5.0 & 8.0 \\
& $2041-50$ & 8.7 & 6.3 \\
Term Spklt - End Veg & $2021-30$ & 10.0 & 19.7 \\
& $2031-40$ & 8.3 & 16.3 \\
& $2041-50$ & 8.7 & 21.3 \\
End Veg - End Ear Gr & $2021-30$ & 8.3 & 20.3 \\
& $2031-40$ & 10.3 & 19.0 \\
& $2041-50$ & 9.0 & 26.0 \\
End Ear Gr - Beg Gr Fil & $2021-30$ & 8.7 & 17.0 \\
& $2031-40$ & 8.3 & 16.3 \\
& $2041-50$ & 8.3 & 18.7 \\
Beg Gr Fil - End Gr Fil & $2021-30$ & 5.7 & 6.0 \\
& $2031-40$ & 8.3 & 7.0 \\
& $2041-50$ & 5.3 & 11.0 \\
\hline
\end{tabular}

Simulated projected temperature and yield variability in mid-century

Although in mid-century climate would be changed with change of mean temperature yet there would be change in temperature variability. The wheat yield in mid-century would be influenced by the masked effect of both change in mean temperature and variability alongwith the changes in other climatic parameters like precipitation and concentration of $\mathrm{CO}_{2}$. Assuming that relationships between yield and weather parameters developed in existing conditions hold, yields were simulated for mid-century. Inter-seasonal variation in Tmax, Tmin and yield during different planting dates under different time slices of MCis presented in Table 2.In different time slices, variability averaged across dates of planting would ranged from 3.7-8.8 percent in Tmax, 2.0 5.9 percent in Tmin would cause $8.6-13.6$ percent variability in wheat yield. Averaged across time slices variability of 5.5 percent in Tmax and 3.8 percent in Tmin would cause 11.2 percent variability in wheat yield. It is interesting to note that projected inter-seasonal variability in MC would be more in Tmax than Tmin, contrary to more variability in Tmin than Tmax in the present time slice.

The variation in yield varied with date of planting, for example, 11.6 percent in October 20, 8.4 percent in November 
5 and 13.6 percent in November 20 planted wheat.Relatively less variation in Nov 05 than other dates show that in MC, yield can be sustained by planting wheat at this date. These results supports our earlier results that decline in wheat yield in $\mathrm{MC}$ can be minimized by delaying planting date by 15 days (Jalota et al., 2013)

The projected intra-seasonal variability in MC would be 7.8 percent in Tmax and 14.6 percent in Tmin, however, at different stages are presented in Table 3 . The variability in different stages ranged from 5-10 percent in Tmax and 626 percent in Tmin. However, amongst the five stages, relativelymore variation (6-26 percent) in Tmin was noticed in three stages viz. term spikelet-end of vegetative, end of vegetative -end of ear growth stage; and end of ear growth -end of grain fill stage. This corroborates the results of the field study i.e. yield remained sensitive to Tmax during germination -term spikelet, and end of vegetative -end of ear growth stage; and to Tmin during during germination term spikelet, and end of vegetative -end of ear growth stage, and end of ear growth-beginning of grain fill stages.

\section{CONCLUSION}

Field data of six wheat seasons (from 2008-09 to 2013-14) reveal that inter-and intra-seasonal variation of $3.4^{\circ} \mathrm{C}$ and $10.3^{\circ} \mathrm{C}$ in Tmax $; 4.6^{\circ} \mathrm{C}$ and $27.5^{\circ} \mathrm{Cin}$ Tmin caused 8.7 percent variation in wheat yield in central Punjab.A strong interaction of year and management interventions implies that the impact of inter-and intra-seasonal variation on wheat yield can be minimized by staggering date of planting with appropriate variety and irrigation schedule. Growing of longer duration varieties in last week of October with adequate irrigation, longer and medium duration in $1^{\text {st }}$ week of November with adequate or deficit irrigation is the practical adaptive measure to minimize impact of temperature variability on wheat yield.

\section{REFERENCES}

Farooq, M, Breley, H. and Palta, J.A. (2011). Heat stress in wheat during reproductive and grain-filling phases. Plant Sci., 30:1-17.

IPCC, Data distribution centre, www.ipcc-data.org/ancillary/ tar-bern.txi.

Jalota, S.K., Kaur, H, Kaur, S. and Vashisht, B.B. (2013). Impact of climate change scenarios on yield, water and nitrogenbalance and -use efficiency of rice-wheat cropping system. Agric. Water Manage., 116:29-38.

Jalota S.K. andVashisht B.B. (2016). Adapting cropping systems to future climate change scenario in three agro-climatic zones of Punjab, India. J. Agrometeorol., 18(1): 48-56.

Kingra, P.K. (2016). Climate variability impacts on wheat productivity in central Punjab. J. Agrometeorol., 18(1): 97-99.

Ladha, J.K., Pathak, H., Tirol-Padre, A., Dawe, D. and Gupta, R.K. (2003). Productivity trends in intensive rice wheat cropping systems in Asia. In: Improving the Productivity and Sustainability of Rice-Wheat Systems: Issues and Impacts. ASA Special Publication, 65:45-76.

Porter, J.R. and Gawith, M. (1999). Temperature and the growth and development of wheat: a review. Eur. J. Agron., 16:23-36.

Subash, N. and Ram Mohan, H.S. (2012). Evaluation of the impact of climatic trends and variability in rice-wheat system productivity using Cropping System Model DSSAT over the Indo-Gangetic Plains of India. Agric. For. Meteorol., 164:71-81.

Vashisht, B.B., Mulla, D.J., Jalota, S.K., Kaur, S., Kaur, H. and Singh, S. (2013). Productivity of rainfed wheat as affected by climate change scenario in northeastern Punjab, India. Reg. Environ. Change, 13:989-998.

Zacharias, Manju, Kumar, S. Naresh, Singh, S.D., Rani D.N.S. and Aggarwal, P.K. (2014). Assessment of impacts of climate change on rice and wheat in the Indo-Gangetic plains, J. Agrometeorol., 16(1): 9-17. 